\title{
High-performance liquid chromatography analysis of circulating insulins distinguishes between endogenous insulin production (a potential pitfall with streptozotocin diabetic rats) and islet xenograft function
}

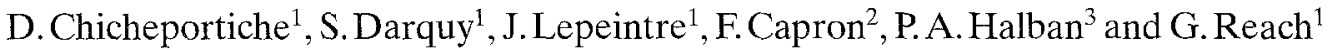 \\ Service de Diabétologie, ${ }^{2}$ Service d'Anatomo-Pathologie, Hôtel-Dieu Hospital, Paris, France, and \\ ${ }^{3}$ Laboratoire de Recherche Louis Jeantet, University of Geneva School of Medicine, Geneva, Switzerland
}

Summary. Porcine islets of Langerhans were microencapsulated according to the alginate-polylysine procedure, and implanted into the peritoneal cavity of 15 streptozotocin-induced $(70 \mathrm{mg} / \mathrm{kg}$ ) diabetic rats (6000 microencapsulated islets per rat). In four animals, a sustained decrease in plasma glucose level below $8.3 \mathrm{mmol} / \mathrm{l}$ was observed for up to nine months. However, it was possible to recover microcapsules from the peritoneal cavity of only one rat, and they were found to be damaged and containing no detectable tissue. When insulin in the plasma of three of these animals was analysed by reversed phase high-performance liquid chromatography, only rat insulins I and II, but not porcine insulin was detectable, indicating unambiguously that at the time of analysis, the correction of diabetes in these animals was due to the function of the recipient's own pancreas rather than the con- tinued, long-term, function of the implanted porcine islets. These data confirm that in this model of diabetes, function of the host pancreas can resume following islet transplantation, leading in turn to the potential for a major bias in the interpretation of the data. In the case of an islet xenograft, when the donor's and recipient's insulins can be separated by highperformance liquid chromatography, this non-invasive analytical method should prove useful for identifying the source of insulin in the circulation, and thus the relative functional status of the endogenous and transplanted islets.

Key words: Microencapsulated, porcine, islets, streptozotocin, diabetic rats, pancreas regeneration, bioartificial pancreas, high performance liquid chromatography.
Pancreas, and in particular islet transplantation for the cure of human diabetes mellitus is currently limited not only by the need for immune suppression, but also by availability of transplantable tissue [1]. To overcome these problems, methods are being developed to permit xenogeneic islet transplantation in the absence of immune suppression. These methods include the immunoprotection of islets by an artificial membrane, leading to the concept of the bioartificial pancreas [2]. Among various approaches, microencapsulation of islets inside an alginate-polylysine membrane [3] is promising, since rat islets placed inside such a membrane were shown in vitro to be protected against the cytotoxic effect of serum from Type 1 (insulin-dependent) diabetic patients [4], to respond rapidly to a glucose stimulation by increasing their insulin production [5], to correct diabetes for several months in allogeneic rats [6] and in mice [7], and to prevent cataract and glomerular lesions in rats [8].

We investigated the ability of microencapsulated porcine islets to correct hyperglycaemia in 15 rats made diabetic with a dose of streptozotocin $(70 \mathrm{mg} / \mathrm{kg}$ body weight) which is usually used in islet transplantation studies [9]. In four animals, a sustained correction of diabetes was observed. However, since the normalization of blood glucose might have been due to a regeneration of the host pancreas [10-14] rather than to the transplanted porcine islets, it was thought necessary to distinguish between these two possible causes for the reversal of diabetes in these rats. This was achieved by analysing plasma insulin by reversed phase HPLC (porcine and rat insulins being readily separable by this method). Only rat insulins could be detected in the circulation of the transplanted animals displaying sustained normoglycaemia, showing unambiguously that the host pancreas regeneration was indeed responsible for the reversal of diabetes. Measurement of pancreatic insulin in these rats confirmed this conclusion. The use of the HPLC method thus prevented serious misinterpretation of our data. Such HPLC analysis of circulating insulin forms, a noninvasive method allowing for long-term monitoring of graft function, should prove to be an essential diagnostic technique applicable in any case of islet xenograft in which the two animal species of insulin can be separated by HPLC. 


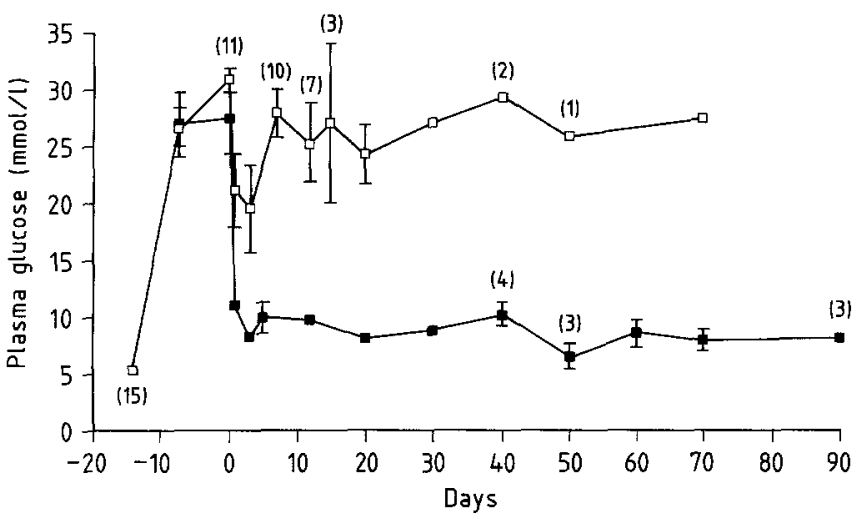

Fig. 1. Plasma glucose concentration within 100 days in streptozotocin-induced diabetic rats transplanted with microencapsulated porcine islets. Transplanted islet failure (open symbols, mean and SEM, $n=11$ ), and prolonged rat glycaemia normalisation (closed symbols, $n=4$ ). Numbers between brackets represent the number of animals

\section{Materials and methods}

Porcine islet isolation and microencapsulation. Porcine pancreases were obtained from pigs directly after slaughter, and islets were isolated by a method involving duct catheterization, inflation of the pancreas with Hank's solution containing type 11 (Sigma, Saint Louis, Mo., USA) collagenase, incubation at $37^{\circ} \mathrm{C}$ followed by mechanical dilaceration of the digested pancreas, and islet purification on a discontinuous albumin gradient. Insulin secretion from islets of Langerhans isolated by this procedure and incubated in Minimal Eagle's Medium containing $5.5 \mathrm{mmol} / 1$ glucose was $23.0 \pm 4.3 \mu \mathrm{U}$ islet ${ }^{-1} .60 \mathrm{~min}^{-1}$. Secretion was $49.6 \pm 7.7 \mu \mathrm{U} \cdot$ islet $^{-1} .60 \mathrm{~min}^{-1}$ when islets were incubated in a medium containing $16.5 \mathrm{mmol} / 1$ glucose and $5.5 \mathrm{mmol} / 1$ theophylline (mean and SEM, $n=5$ different isolation procedures, $p<0.01$ ). Porcine islets were then microencapsulated by the alginate-polylysine method described by $O$ 'Shea et al. [7]. Insulin secretion by microencapsulated islets was $5.5 \pm 0.9 \mu \mathrm{U} \cdot$ islet $^{-1} \cdot 60 \mathrm{~min}^{-1}$, and $18.6 \pm 4.3 \mu \mathrm{U} \cdot$ islet $^{-1} .60 \mathrm{~min}^{-1}$ under the same basal, and stimulatory, conditions, respectively $(n=12, p<0.01)$.

\section{Implantation of microencapsulated porcine islets into diabetic rats}

Animals. Fifteen streptozotocin-induced diabetic Wistar rats $(250-300 \mathrm{~g})$ were used as graft recipients. Experimental diabetes was induced by i.v. injection of overnight fasted rats with $70 \mathrm{mg} / \mathrm{kg}$ body weight of streptozotocin (Zanossar, Upjohn, France) diluted in citrate buffer, $\mathrm{pH}=4.2$. Blood samples for determination of non fasting plasma glucose concentration were performed by bleeding the orbital sinus. Only rats with persistent (repeated tests over a 15-day period) plasma glucose concentrations $>20 \mathrm{mmol} / \mathrm{l}$ in the fed state were used as transplant recipients. Diabetic rats under ether anaesthesia received intraperitoneally about 6000 microencapsulated porcine islets.

\section{Assessment of the role of microencapsulated porcine islets in the correction of diabetes}

In four animals, a sustained decrease in plasma glucose concentration was observed. In order to verify that microencapsulated islets were indeed responsible for this effect, the following procedures were performed, at $42,90,270$, or 305 days: The abdominal cavity was opened under ether anaesthesia, and carefully examined to recover the microcapsules. These capsules were fixed in Bouin's solution. In three animals, the rats received $0.6 \mathrm{~g} / \mathrm{kg}$ arginine and $0.5 \mathrm{~g} / \mathrm{kg}$ glucose before anaesthesia, and $10 \mathrm{~min}$ later, blood was drawn through an aortic catheter for the determination of insulin species (see below). Finally, the pancreas was removed from the four animals and insulin extracted. The pancreas was homogeneized in acid ethanol ( $750 \mathrm{ml}$ ethanol, $15 \mathrm{ml} \mathrm{HCl}, 235 \mathrm{ml}$ distilled water), and the insulin and protein contents were determined in the extract, by RIA using rat insulin as standard, and by the Bradford colorimetric assay using bovine serum albumin as standard, respectively.

$H P L C$ analysis of plasma insulin immunoreactivity. In order to concentrate and partially purify insulin, the plasma were loaded onto C18 Sep-Pak cartridges (Water Associates, Milford, Mass., USA). After serial washing steps [15], insulin was eluted from the cartridges in $45 \%$ acetonitrile; $1 \%$ trifluoroacetic acid (TFA); $54 \% \mathrm{H} 20$. The eluted material was lyophilised (after initial evaporation of the acetonitrile) and, finally, dissolved in $200 \mu 10.1 \% \mathrm{TFA}$. The total volume of plasma loaded onto the cartridges was $4.31 \pm 0.07$ and $4.39 \pm 0.26 \mathrm{ml}$ (mean $\pm \mathrm{SEM}, n=3$ ) for transplanted and normal rats respectively. The total amount of insulin loaded was $21.5 \pm 3.3 \mathrm{ng}$ and $23.1 \pm 3.5 \mathrm{ng}$ for the two groups. The recovery of insulin immunoreactivity from the Sep-Pak cartridges was similar for the two groups $(72.7 \pm 3.5 \%$ vs $80.9 \pm 4.2 \%$ for transplanted vs normal rat plasma).

Separation of porcine and rat insulins was achieved by reversed phase HPLC using a modification of the system we have previously described $[16,17]$. The column was an Altex $5 \mu \mathrm{m}$ Ultrasphere ODS (Beckman, Fullerton, Calif., USA). Insulin was eluted using a linear gradient of 32 to $35 \%$ buffer B over 80 min, where buffer B was $90 \%$ acetonitrile; $10 \% \mathrm{H} 20$, and buffer $\mathrm{A}$ was triethylamine-phosphoric acide-sodium perchlorate as described in [16] and [17]. Authentic porcine insulin (Eli Lilly and Co, Indianapolis, Ind., USA) was mixed with rat insulins I and II (obtained by HPLC purification of acid extracts of isolated rat islets) in roughly equal amounts and injected onto the column as standards. Fractions eluting from the column $(0.7 \mathrm{ml} /$ fraction; flow rate $1 \mathrm{ml} / \mathrm{min})$ were collected into glass tubes containing $75 \mu \mathrm{l}$ of $0.5 \mathrm{~mol} / \mathrm{l}$ borate; $1 \% \mathrm{BSA} \mathrm{pH} 9.3$, and after evaporation of acetonitrile, frozen and lyophilised. The dried samples were dissolved in $1 \mathrm{ml} 0.2 \mathrm{~mol} / 1$ glycine; $0.1 \%$ BSA; pH 8.8 . Insulin was measured in each fraction by RIA using rat insulin as standard. It should be noted that the antiserum used for these assays (guinea-pig anti-porcine insulin; a generous gift of Dr. G. C. Weir, Boston, Mass., USA) displays greater reactivity towards porcine insulin than rat insulin, thereby favouring the detection of the former insulin species. The recovery of immunoreactive insulin from the HPLC system was quantitative as demonstrated previously [16].

Insulin assay of islet incubation and ratplasma samples. Immediately after sampling, the aliquots were diluted with Krebs bicarbonate buffer and stored at $-20^{\circ} \mathrm{C}$. The insulin concentration was assayed by the radioimmunological method [18] using porcine insulin as standard. Proteins were assayed with the method of Bradford [19].

\section{Statistical analysis}

All results in text and figures are expressed as mean and SEM. In the in vitro experiments, we first calculated the mean of the data of five different incubation wells. Then, the mean and SEM of these mean values were calculated for the 5 (free islets), or 12 (microencapsulated islets), experiments. Two-tailed paired Student's $t$-test was used to determine the statistical significance of the data.

\section{Results}

Outcome of microencapsulated porcine islet transplantation in diabetic rats. Fifteen streptozotocin-induced diabetic rats (mean glycaemia $27.0 \pm 1.4 \mathrm{mmol} / \mathrm{l}$ ) received 


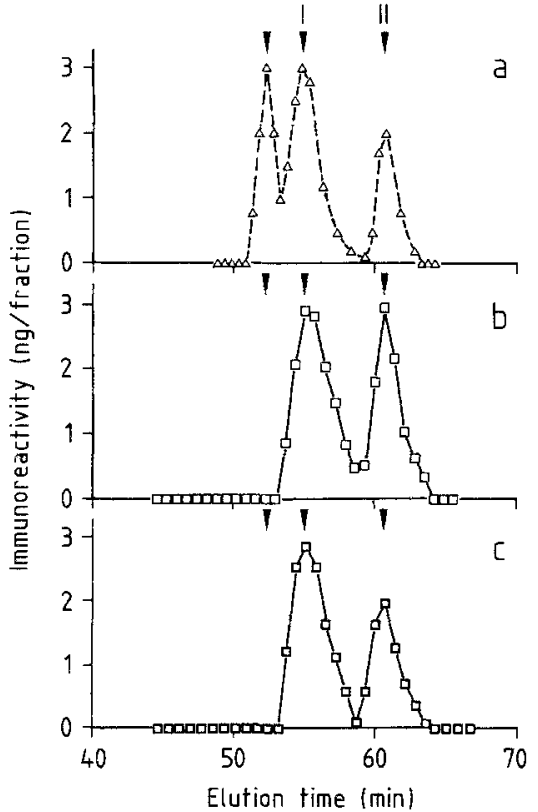

Fig. 2a-c. Analysis of circulating insulin by reversed phase HPLC. Samples of plasma were pre-purified and concentrated by Sep-Pak cartridge and then subjected to HPLC. Representative elution profiles for insulin immunoreactivity are shown for: Panel a: Mixed porcine and rat insulin standards; panel b: plasma from control rat; panel c: plasma from a normoglycaemic transplanted rat. The arrows indicate the elution times for porcine insulin and rat insulins I and II, respectively

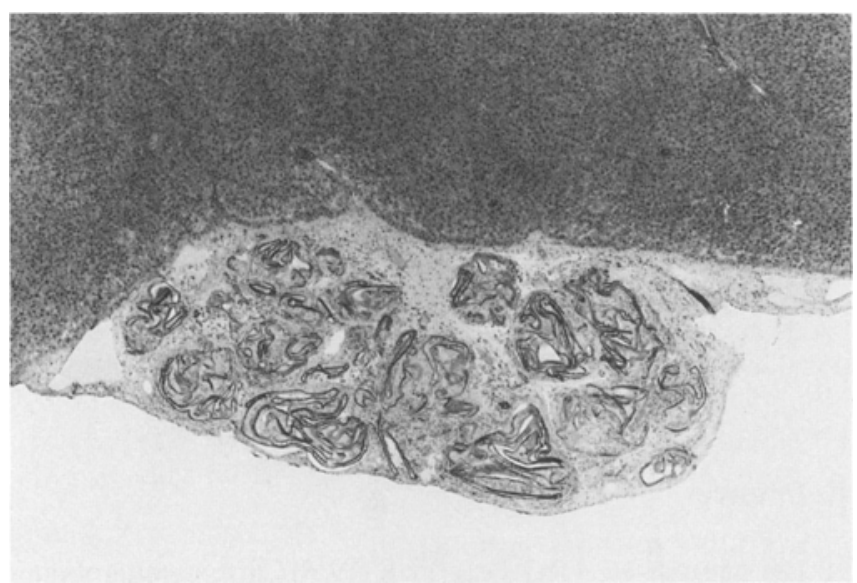

Fig. 3. Light photomicrograph of removed microcapsules (magnification: 14)

intraperitoneal transplants of 6000-7000 microencapsulated porcine islets. As shown in Figure 1, in 11 animals (open symbols), after a slight and transient decrease in plasma glucose concentration (from $27.0 \pm 1.8$ to $18.7 \pm 3.8 \mathrm{mmol} / \mathrm{l}$ ) from 1 to 3 days after the transplantation, plasma glucose levels increased again to reach $28 \mathrm{mmol} / \mathrm{l}$. Six of these animals died spontaneously at different moments after transplantation, and the other five were killed for histological study. The closed symbols represent the prolonged normalization of blood glucose following xenograft transplantation in four diabetic rats. The mean plasma glucose level decreased from
$27.2 \pm 2.9 \mathrm{mmol} / 1$ on the day of transplantation to $10.0 \pm 1.3 \mathrm{mmol} / 1$ the next day, reaching $8-10 \mathrm{mmol} / \mathrm{l}$ for several weeks $(42,90,270$, and 305 days $)$.

\section{Characterization of circulating insulin species}

In order to characterise the origin of the insulin in the circulation of the transplanted rats, blood was collected $10 \mathrm{~min}$ after iv glucose and arginine. Insulin immunoreactivity in the plasma was then analysed by reverse phase HPLC. Typical elution profiles are shown in Figure 2, the upper panel (A) shows a profile for a mixture of porcine and rat insulin standards, with clear identity of the three types of insulin present. When plasma from a control rat was analysed (panel B), only rat I and II insulins were detected. Strikingly, plasma taken from one of the normoglycaemic transplanted rats similarly showed only rat insulins with no detectable porcine insulin (panel C). The same was found for two other normoglycaemic transplanted rats (not shown). In order to exclude the possibility of an artifact due to sample handling, an additional control was performed. Rat plasma containing approximately $4 \mathrm{ng} / \mathrm{ml}$ rat insulin was supplemented with $4 \mathrm{ng} / \mathrm{ml}$ porcine insulin. The plasma was passed through a Sep-Pak cartridge as for plasma taken from control of transplanted rats, and then chromatographed by HPLC. The profile of immunoreactivity revealed a well defined peak of insulin eluting at the position of the porcine insulin standard, in addition to the two rat insulin peaks. Furthermore, the ratio of porcine to rat insulin was as predicted from the relative amounts of these products known to be present in the initial plasma sample. This control confirms that there was no selective loss of porcine insulin during plasma analysis.

\section{Histological studies and insulin content of the pancreas}

The four rats, in which plasma glucose was normalised for a prolonged period of time, were killed, and their pancreas removed for histological examination and estimation of insulin content. In only one rat was it possible to recognise microcapsules on the surface of the liver, and histological assessment showed damaged microcapsules surrounded by a fibrotic reaction (Fig.3). No islet was detectable inside the microcapsules. The insulin content of the pancreas of the four transplanted animals displaying a sustained blood glucose level normalization was greater than that observed in normal rats ( $211 \pm 72$ vs $82 \pm 14 \mathrm{IU} /$ gram of protein, respectively, mean $\pm \mathrm{SEM}, n=4$ ). By contrast, in the case of two transplanted animals in which no prolonged decrease in blood glucose levels was observed, the insulin content of their pancreas was 5.4 and $7.2 \mathrm{IU} / \mathrm{gram}$ of protein, respectively.

\section{Discussion}

Porcine islets were isolated and microencapsulated, and islet function monitored by measuring insulin release in vitro. Insulin release in stimulatory medium (glucose 
$16.5 \mathrm{mmol} / \mathrm{l}$ and theophylline $5 \mathrm{mmol} / \mathrm{l}$ ) was twice that observed in basal medium (glucose $5.5 \mathrm{mmol} / \mathrm{l}$ ). A similar response was observed by Ricordi et al. with porcine islets of Langerhans [20]. The microencapsulated porcine islets were injected into 15 streptozotocin induced diabetic rats (6000-7000 islets/rat). Eleven transplanted rats displayed a modest and short-lived decrease in plasma glucose concentration. In four animals, a prolonged major improvement in the fed blood glucose level was observed. In three of these animals, plasma glucose concentrations during an intravenous glucose tolerance test were similar to those observed in normal rats (results not shown). It would have been tempting to claim that in these four rats, in which a sustained correction of hyperglycaemia was observed, the transplanted islets had reversed the diabetes and were continuing to function several months after transplantation. However, since spontaneous pancreas regeneration has been demonstrated in this experimental model of diabetes [10-14] it was felt possible that such regeneration may have accounted for the normoglycaemia observed in some of the transplanted rats. Since it was not possible to remove all of the microencapsulated islets in order to demonstrate a reversion to a diabetic state after graft removal, as would be the case with islets transplanted into the spleen [21], under the kidney capsule [22] or when using islets containing hollow fiber devices [23], we used two approaches to evaluate the relative contribution of endogenous pancreas and of the transplanted islets.

First, the recipients own pancreas was found to contain even more insulin than controls. Such was not the case for transplanted rats in which diabetes was not corrected. Whether this was due to true islet regeneration or to the functional recovery of islets having survived from the streptozotocin injury requires further investigation (i.e. the determination of mitotic index). The observation of a higher insulin content in the pancreas of the normoglycaemic recipients than that found in the pancreas of normal rats may also reflect the induction of microadenomas following streptozotocin injection.

Neither the fact that the recipient's own pancreas did contain insulin, nor the fact that in the single case in which microcapsules could be recovered from the fatty peritoneal cavity of these animals no surviving islet tissue was visible, refutes per se the possibility for the functional survival of some microencapsulated islets. This was, however, definitively ruled out by the separation of rat and porcine insulin by reversed HPLC. The results showed that in the transplanted rats only rat insulins could be detected in the circulation following stimulation of insulin release by i.v. injection of glucose and arginine. Based upon the sensitivity of the immunoassay (minimal detectable concentration $0.1 \mathrm{ng} / \mathrm{ml}$ ), the cross reactivity of the antiserum for porcine and rat insulin and the volume of plasma injected onto the HPLC column, it is possible to estimate that porcine insulin present at a concentration of $0.2 \mathrm{ng} / \mathrm{ml}$ in plasma would have been detectable. Since the total insulin concentration in the plasma samples was approximately $4.5 \mathrm{ng} / \mathrm{ml}$ it will be apparent that if porcine insulin accounted for only $5 \%$ of this total insulin reactivity it would have been detectable; however, this was not the case. The presence of rat, but not porcine, insulin in the circulation of the normoglycaemic transplanted rats clearly indicates the intervention of the host pancreas in the face of a nonfunctional graft at the time of the study.

Several mechanisms might be responsible for the graft failure observed in this study, including the fragility of the isolated porcine islets, or of the microcapsules, or an inadequate biocompatibility of the alginate material leading to fibrosis and capsule destruction. However, whatever the mechanism, the remission of diabetes observed in this study stresses the need for additional analyses aside from those usually performed in these kind of studies (random blood glucose, or even radioimmunological measurement of insulin in plasma). Xenograft (in this example porcine islets transplanted into rats, but any other combination allowing for HPLC separation of the insulins produced would be equally suitable), combined with HPLC analysis of insulin species in the circulation, provides a unique opportunity to test whether the graft is, as normally supposed, indeed functioning on a long-term basis. Moreover, this determination should prove useful as an index of the functional status of the implanted or host islets at any time after transplantation since the method is noninvasive (the volume of blood being a limiting factor in small animals such as mice).

Although it should be stressed that our data and conclusions in no way imply that the results of other studies employing microencapsulated islets in a similar model of diabetes have necessarily been misinterpreted, we suggest that appropriate control experiments must be introduced in the critical evaluation of microencapsulation of islets of Langerhans as a bioartificial pancreas, and that another model of diabetes, completely and irreversibly insulinopoenic, such as the BB rat, might be more appropriate for further studies.

Acknowledgements. We thank Ms. J. Rouchette, Ms. N. Klages and Ms. C. Meyer for expert technical assistance. This work was supported by C.N.R.S.-INSERM, ATP Organes Artificiels 1986, l'Aide aux Jeunes Diabétiques, by grant $n^{\circ}$ DK35292 from the National Institutes of Health (PAH) and by the Greenwall Foundation.

\section{References}

1. Hering BJ, Bretzel RG, Federlin K (1988) Current status of clinical islet transplantation. Horm Metab Res 20:537-545

2. Reach G, Jaffrin MY (1986) Les pancréas bioartificiels. Médecine Sciences 2: 87-93

3. Lim F, Sun A (1980) Microencapsulated islets as bioartificial endocrine pancreas. Science 210:908-910

4. Darquy S, Reach G (1985) Immunoisolation of pancreatic B cells by microencapsulation: an in vitro study. Diabetologia 28 : $776-780$

5. Chicheportiche D, Reach $G$ (1988) In vitro kinetics of insulin release by microencapsulated rat islets: effect of the size of the capsules. Diabetologia 31: 54-57

6. O'Shea GM, Goosen MFA, Sun AM (1984) Prolonged survival of transplanted islets of Langerhans encapsulated in a biocompatible membrane. Biochim Biophys Acta 804: 133-136

7. O'Shea GM, Sun AM (1986) Encapsulation of rat islets of Langerhans prolongs xenograft survival in diabetic mice. Diabetes 35: 943-946

8. Sun AM, O'Shea GM, Gharapetian H (1985) Artificial cells containing islets as bioartificial pancreas. In: Nosé Y, Kjellstrand C, 
Ivanovitch $\mathrm{P}$ (eds) Progress in artificial organs. ISAO Press, Cleveland, pp 601-606

9. Rabinovitch A, Alejandro R, Noel J, Brunschwig JP, Ryan US (1982) Tissue culture reduces Ia antigen-bearing cells in rat islets and prolongs islet allograft survival. Diabetes 31 [Suppl 4]: 48--54

10. Kruszinska YT, Home PD, Morley A, Alberti KGMM (1986) Preservation of islet function and morphology after transplantation into high dose streptozotocin-diabetic rats. Diab Res 3: $175-181$

11. Brekke IB, Alumets J, Sundler F (1983) The duct-ligated pancreas transplant and its effect on the islet cellular composition of the host pancreas. A morphometric analysis. Cell Tissue Res 231: 205-213

12. Richardt M, Menden A, Bretzel RG, Federlin K (1984) Islet transplantation in experimental diabetes of the rat. B-cell regeneration following islet transplantation. Preliminary results. Horm Metab Res 16: 551-552

13. Slipjepcevic M, Helmke K, Federlin K (1975) Islet transplantation in experimental diabetes of the rat. Comparative studies, pancreatectomy streptozotocin. Horm Metab Res 7:20-25

14. Trimble ER, Karakash C, Malaisse-Lagae F, Vassutine I, Orci L, Renold AE (1980) Effects of intraportal islet transplantation on the transplanted tissue and the recipient pancreas. Functional Studies. Diabetes 29:341-347

15. Cohen RM, Given BD, Licinio-Paixao J, Provow SA, Rue PA, Frank BH, Root MA, Polonsky KS, Tager HS, Rubinstein AH (1986) Proinsulin radioimmunoassay in the evaluation of insulinomas and familial hyperproinsulinemia. Metabolism 35: 1137-1146

16. Halban PA, Rhodes CJ, Shoelson SE (1986) High-performance liquid chromatography (HPLC): a rapid, flexible and sensitive method for islet proinsulin and insulin. Diabetologia 29: 893-896
17. Rhodes CJ, Lucas A, Halban PA (1987) Glucose stimulates the biosynthesis of rat I and II insulin to an equal extent in isolated pancreatic islets. FEBS Lett. 215: 179-182

18. Morgan CR, Lazarow A (1983) Immunoassay of insulin: two antibody system: plasma insulin levels of normal, subdiabetic and diabetic rats. Diabetes 12: 115-126

19. Bradford M (1976) A rapid and sensitive method for the quantification of microgram quantities of protein utilizing the principle of protein-dye binding. Analitical Biochemistry 72:248-254

20. Ricordi C, Finke EH, Lacy PE (1986) A method for the mass isolation of islets from the adult pig pancreas. Diabetes 35: 649-653

21. Sandler S, Andersson A (1982) Survival of intrasplenicaly implanted islets in mice with experimental insulitis and hyperglycemia. Diabetes 31 [Suppl 4]: 78-82

22. Reece-Smith H, McShane P, Morris PJ (1982) Glucose and insulin changes following a renoportal shunt in streptozotocin diabetic rats with pancreatic islet isografts under the kidney capsule. Diabetologia 23: 343-346

23. Altman JJ, Houlbert D, Callard P, McMillan P, Solomon BA, Rosen J, Galletti PM (1986) Long-term plasma glucose normalization in experimental diabetic rats with macroencapsulated implants of benign human insulinoma. Diabetes 35: 625-633

Received: 22 January 1990

and in revised form: 17 April 1990

Dr. G. Reach

Service de Diabétologie

Hôtel-Dieu

1, Place du Parvis Notre-Dame

F-75004 Paris

France 